\title{
Managing Human Resources: From Commodity Connotation to Human Capital
}

\author{
Abhilasha Singh \\ American University in the Emirates, Dubai International Academic City, Dubai, UAE \\ abhilasha.singh@aue.ae
}

Received date: 14 August 2013; Accepted date: 17 February 2014; Published date: 19 May 2014

Academic Editor: Wendy Ming-Yen Teoh

Copyright ( 2014. Abhilasha Singh. Distributed under Creative Commons CC-BY 3.

\begin{abstract}
Achieving organizational excellence is not possible without visible involvement of leadership. This is however, a crucial question; whether leader's participation is essential or there are other factors that effect on the implementation of excellence at the strategic management level. The following case presents the issues and challenges in managing employees and the vital commitment from the top management. This case has a difficulty level of three to four, and is appropriate for both undergraduate and graduate courses on Leadership, Strategy, Organizational Development and Managing and Developing Human Capital. This case is designed to be taught in three hour class room session, and is expected to require minimum two hours of outside preparation by students. The learning objective is to understand the talent landscape in the Kingdom of Saudi Arabia region as it exists today and to explore issues of managing human resources, including psychological contract, job satisfaction, reward strategy to attract and retain high - performers for enhancing the employee satisfaction level and hence their productivity.
\end{abstract}

Keywords: human resources, job satisfaction, employee satisfaction

\section{Introduction}

Mr. Ahmed sat down for his evening cup of tea, perplexed with the situation he was faced with. He was a strong advocate of the employee care approach as part of which, issues were meant to be dealt through personalized perspectives and not through a financial one. Yet the present company, where he had just been employed as a Human Resource Manager has never implemented this approach or believed it could ever work. It was with these pressing concerns that Mr. Ahmed came to the conclusion that he would have to start from

scratch to ensure that all necessary issues were addressed and all problems were adequately resolved. There was a need to understand the employees' concerns, and create a normative and affective dimension to an employee's organizational commitment. Furthermore, the employee turnover was very high and thus creating an urgent need for employee retention which was another concern. Mr. Ahmed 
wished to make the employees experience the benefits and the support that the organization has to offer. 'How', was the question that irked him. He was of the opinion that the only way to promote Organizational Commitment and Job Satisfaction was to ensure that the employees be considered as source of ideas and not just pair of hands. He was realizing that the missing element is nothing but treating employees like consumers. He had done a great deal of research on the employee care approach, and his vast work experience as well provided impressive literature on the subject, but certainly the present challenging situation is going to test his vast knowledge on the subject to the fullest.

Over the course of this case study, we shall analyse how Mr. Ahmed went about with this challenging task of implementing the employee care approach and the benefits that it has had for Qudurat LLC.

\section{Background of the Kingdom Of Saudi Arabia}

The Kingdom Of Saudi Arabia is the second largest landmass in western Asia and the second largest Arab country after Algeria. It was established in the year 1932 under the leadership of Abdul Aziz bin Saud from where the country gets its name. Since its establishment in the year 1932, Saudi Arabia has been steered to an era of peace and prosperity under the wise leadership of the royal family. It is for this reason that it is referred to as an absolute monarchy. Saudi Arabia possesses the largest oil reserves in the world which accounts for $90 \%$ of its exports and nearly $75 \%$ of all government revenues. The Kingdom is also the home of two of the holiest places in Islam: the Masjid Al Haram and the Masjid Al Nabawi in Mecca and Medina. Though most of the revenues of Saudi Arabia are generated through Oil, the government seeks to promote private employment by privatizing various industries. Among these are power and telecommunication. However, water shortages and population increases have brought about a certain degree of inflation in the economy. To ensure employment for all locals, Nitaqat program is being followed by the Saudi government. This decree ensures that all organizations employ a certain percentage of Saudi nationals. According to this program all firms are labelled in 4 colours; Red, Yellow, Green and Silver. Firms with Red will not be granted any more foreign visas as they do not meet the minimum requirements of Saudization. A similar situation prevails for the Yellow labelled companies but they will be given a grace period until they meet the requirements of Saudization. Companies in the Green zone are labelled to be in the safe zone, allowing for issuing of foreign visas as they have employed adequate number of locals. The Silver companies are also categorized as being in the premium position to employ foreign workers. It is through this very impressive program that the government is ensuring adequate recruitment for the local population.

The Qudurat LLC's Headquarters that we shall analyze in this case is based in Dammam as is the protagonist Mr. Ahmed. Dammam is the industrial capital of the eastern province of The Kingdom Of Saudi Arabia with two industrial cities and a port. The judicial and administrative bodies of this region are located in this city. It is the largest city in the eastern province and the third largest in Saudi Arabia after Jeddah and Riyadh. It is the city that Mr. Ahmed would be posted to after being handed his new assignment as Corporate HR Manager for Qudurat LLC. The city is strategically well poised as it is very well connected by road, rail, air and sea and has emerged as the industrial hub for all businesses as well as tourism, attracting a large influx of both skilled and non skilled workers. This obviously leads to a wide cross section of both immigrant and non immigrant people, compelling the organizations to establish a specific department to manage their human capital that was previously taken care of by an administrative department.

\section{Qudurat LLC Profile}

\section{Vision}

A Winning Industrial Leader Creating Superior Values for Business \& Community

Winning the confidence and trust of our markets and stakeholders is inherently 
built in our nature.

Industrial leadership and competence takes us beyond manufacturing and into other industries.

Business and Community are jointbeneficiaries of our superior value creation towards mutual prosperity.

\section{Core Values}

Honesty \& Integrity - We believe goodwill and good reputation is core to our business. We uphold Honesty, Integrity, Professionalism and a high level of business ethics. We observe prudence and fairness in dealings with our stakeholders.

Customer \& Excellence- We are diligent about understanding and fulfilling our customers' needs. We strive to please our customers with excellence in quality and services. We listen to our customers and "go the extra mile to satisfy them.

Innovation \& Change - We are passionate about meaningful innovation. We are a learning organization. We learn from our experiences and global best practices, and we innovate to create leading local solutions leveraging on world class knowledge. We embrace positive change brought forth by innovation and aspirations to grow our business

Leadership \& Prudence -We cultivate talent and leadership to create sound business solutions, to best meet our customer needs, and to develop markets, people and shareholder values. We do so by optimizing the use of funds, resources, materials, and technologies. We build prudence and cost-effectiveness in our leadership culture passing on benefits to our customers.

Community \& Prosperity -We believe in mutual prosperity. We aspire to thrive in business while bringing progress and prosperity to our own people and communities where we operate. Our culture, our ideas, our practices, our environmental concern, and our team work lead us to creating superior values for people and communities around us.

\section{Overview}

Founded in 1998 and headquartered in Dammam, Saudi Arabia, Qudurat LLC Investment Company (Qudurat LLC) is a leading manufacturing and fabrication group that provides products, engineering systems and services for the construction industry. Its product portfolio includes pre-engineered steel buildings (PEB), structural steel products, air conditioning systems, air cooled heat exchangers, district cooling and utility services, process equipment, transmission and telecom towers, open web joists and steel decks, process furnaces' products, aerated and precast concrete products, architectural glass processing, fiberglass insulation and engineered plastic foams' solutions.

The company sells its products in more than 90 countries with manufacturing facilities in Saudi Arabia, United Arab Emirates, Egypt, Austria, India, Vietnam and

Italy.

Qudurat LLC employs more than 10,000 people in 55 countries and derives $30 \%$ of its revenues from outside Saudi Arabia.

For the year ended 31 December 2010, Qudurat LLC posted a turnover of SAR 4.018 billion/USD 1.072 billion, a decline of $4.4 \%$ over 2009 , with net profit, after Zakat contribution, of SAR 211.1 million/USD 56.3 million. Post Zakat Earnings Per Share during 2010 dropped to SAR 3.52/USD 0.94 from SAR 3.84/USD 1.02 representing 8.3 percent decline. Shareholders' equity grew by $8.6 \%$ to SAR 1.399 billion/USD 373 million. Export sales accounted for SAR 1.112 billion/USD 297 million.

Qudurat LLC shares are actively traded on the Saudi Stock Exchange (Tadawul).

\section{Corporate Role}

Qudurat LLC develops and supports the 
vision and strategic path of all its sector businesses through group-wide strategic initiatives and its "Corporate Shared Services" functions of Finance, Administration and Human Resources, Information Technology, Corporate Communications and Legal Affairs. Its objectives are closely drawn to achieve the following strategic ends:

- A commitment to new product development through the use of advanced technology and the consolidation of IT environments.

- Maintenance of the highest quality assurance standards, reflected in a range of international quality accreditations.

- The continual expansion and development of international markets, while maintaining leadership in the home market of Saudi Arabia.

- Strategic acquisitions to complement the strengths of its sector businesses. Strategic alliances with selected multinational companies to increase international presence and market share.

- Investment in training and career development for employees.

\section{Operations}

Qudurat LLC is comprised of five sectors: Steel, HVAC, Glass, Insulation, and Concrete.

\section{Size of the Organization}

In September 2009, when Mr. Ahmed was first given charge of the company's HR he was responsible for a total pool of more than 8000 employees in Saudi Arabia. This was followed by an added responsibility of more than 3000 company employees located worldwide. Although this project was handled with much aplomb by $\mathrm{Mr}$. Ahmed, but he soon realized that the whitetail problem with the company was a lack of employee care approach. The incentives provided were purely financial and not intended to boost the morale in any way. Considering such a large pool of employees from so many diverse cultures, nations and backgrounds, it was necessary to find a common form of motivation to ensure that the employee care approach was being followed. A variety of measures were taken to achieve the objective of satisfied and motivated workforce. The biggest drawback was the current turnover percentage/attrition rate in the company, which was very high. There was an innate necessity to retain employees, attract talent, satisfy the employees and increase productivity. The economic changes impacted the employees' lives to big changes, especially the inflation that Saudi Arabia experienced as a result of the world wide recession and this affected all employees ranging from labourers to senior management.

\section{Case Timeline}

\section{September 1st, 2009}

Mr. Ahmed joined the organization on September $1^{\text {st }}, 2009$. This was his first day at work when he was given a tour of the organization by his senior. As mentioned before, Qudurat LLC was facing a high turnover and due to this, on his very first day of joining, Mr. Ahmed was welcomed by many resignations to sign off! It was just within a week when Ahmed was settling down to work that two employees, who were labourers at the Dammam plant came up to Mr. Ahmed and expressed their desire to resign, citing the fact that they had not been home for the last 2 years as reason for doing so. This was in addition to the subtle comments made during the discussions that though they receive their pay but they were deeply affected by the absence of any incentives and other benefits at work. This set Mr. Ahmed to ponder on the employees that were being treated as a pair of hands only and not as a source of ideas. Indeed, there was an exigency and something needed to be done fast.

Mr. Ahmed who had done an in-depth research on this subject recollected his earlier knowledge on companies which had successfully implemented the employee care approach. Premier among these was the example of SAS which had started with the distribution of free M\&Ms to all 
employees as part of their employee care approach. There was no such approach at Qudurat LLC though and the staffs were highly de-moralized and de-motivated. It seems to him that even the basic needs of the employees were not being satisfied. Mr. Ahmed adeptly handled the situation; however, it got him thinking about a start.

\section{November, 2009}

It was early November when Mr. Ahmed noticed that there was a large segment of labourers who often felt uncared for and unwanted. There was no one to whom they could address their problems and often felt at the receiving end, consequently hampering the work output and lowering the overall productivity. At the same time, there was also a large segment of middle management who felt they were extremely neglected, with no work autonomy, especially when it came to the decision making. This led to sabotaging and made them very conventional in their approach thus, ensuring that new ventures were not being taken in any form! This was predominantly due to the rejection that the employees feared facing, if they express themselves.

The company, in addition, was facing a dead weight problem. There were many cases of mediocre recruitment as a result of which employees merely manned their posts day after without providing any sort of output to the organization in terms of productivity. As a result of this, the company suffered paying salaries to all those who lacked any sort of commitment or skill to their jobs and yet did not display any organizational commitment. Clearly, a well crafted strategy was required to put an end to all problems but certainly this will take some time and has to be induced incrementally.

\section{March 2010}

When the world was facing the global financial crisis, the Kingdom of Saudi Arabia was almost insulated from the global downturn, and the country's excellent cash flow, liquidity, and its windfall of astounding oil profits throughout the decade left the Kingdom in a strong position but the concept of investing in the human capital was still under question. Yet, in the wake of the New Year, another factor that was bothering Mr. Ahmed was the encashment of holidays by employees. The employees were happy but their overall fatigue was clearly reflected in their quality of work. The question to ponder on was to incorporate some flexible benefits' plan and to provide some sort of a break from their daily routine and not just another pay increase.

Overwhelmed with the issues while determined to bring excellence, he observed the strong subjectivity in the appraisal or employee evaluation system in the company. This meant that there was no objective way to show who was contributing how much to the company. The exit interviews which were held in large numbers due to the high employee turnover were also not an unbiased indicator of the employee issues/dissatisfaction, as most employees either feared of not having final settlement done or were simply dishonest to ensure a good letter of recommendation when they left.

Adding to many other issues was the work life balance. The lower categories of labourers were not eligible for the Family Status. Consequently, their families were not included in the medical coverage and those were major concerns for them to either not bring their families or keep working mechanically to satisfy the financial aspirations.

\section{April - August 2010}

Mr. Ahmed knew that every HR team faces problems both in the running of their department and in the consistent enforcement of policies across the company in general, nonetheless he was certain that employees are the lifeblood of every company and keeping them satisfied, providing the skills and experience is required to keep productivity levels up. Moreover, the employees need to be satisfied without compromising the company interests in the process. He began taking his personal note on where the companies fell short, including but not limited to, employee retention. He has no doubt that employee retention or rather 
focussed talent retention is a fine balancing act between company culture, remuneration and incentives. He decided he will introduce and implement all necessary changes in the following 6 months. Based on his observations he made a detailed report on the shortfalls of the company with considering more or less the following points:

Understanding Employee Concerns: The employee concerns were not being adequately addressed, and based on the current inflation, there were no changes in their salaries. The approach that merely increasing salaries would increase employee commitment to the organization was wrong, yet an accurate record of the combinations of factors was needed to ensure that the agreed packages are taking into consideration the internal and external equity factors.

Rest Holidays: The concept of 'piece-rate plan' was still in practice at Qudurat and employees were happy with this financial model, but the concern of Mr. Ahmed was the quality of work. The long daily working hours with six days a week left many completely exhausted with no zeal at work place. Moreover, many employees preferred to work during the weekend to satisfy their financial needs.

Annual Vacations: The provision of annual 'paid' leave for the employees was only once in every two years. This was especially felt by the expatriates as they were on two year contracts, which means that such employees were away from their homes in camps for a very long time. This was having a negative impact on the work, on the perceived organizational support and hampered the overall productivity of the company. There was no other annual recreation or annual event for the employees and hence there was a tendency to approach work as drudgery.

Family Status: It was surprising to note that currently Qudurat was not having medical care for labourers who were on 'single' status. This was leading to high insecurity amongst the workers leaving them thinking about their families' situation in case of adversity.
Food and Social Activities: Except for meeting informally with their co-workers during the dining time, there was no recreational activity in the camps, which could potentially be a motivating factor for workers. A dearth in all forms of recreation was observed. There was no sport or cultural events for employees as a means of refreshment. Moreover, the food at the camps was often below par and not catering to the tastes of the employees. This further led to a devastating ripple effect that was not only hurting the bottom line but also disrupting the productivity and damaging the morale.

Promotion: The lack of a transparent and systematic company policy regarding promotion was hampering the commitment, loyalty and professionalism of employees. There was no performance appraisal system in place for the assessment of workforce skills and/or regulatory compliance. Consequently, there was low morale among employees who did not strive for more or work hard for improving the quality and productivity of work.

Succession Planning System: in the absence of a careful assessment of workforce skills the increased employee turnover was all the more challenging with no immediate replacement available. Moreover, the issue that was neglected was that there was a large segment of experienced employees who were due to retire in the next 3 years. There was no preparedness or thought in process to assume the new roles! Undoubtedly, a systematic succession planning system was needed to be put in place so that when these employees quit, there would be an adequate and experienced staff to man their posts.

Recruitment and Selection: adding to the challenges of having 'no performance appraisal system' in place was the fact that there wasn't any systematic policy on recruitment and selection that was focussed on talent attraction and/or retention. Whether to complement the existing workforce or to replace the staff lost through voluntary/involuntary attrition, the recruitment was one of the major challenges facing the Human 
Resources' department in Qudurat. The process of short listing or filtering candidates was inefficient and Mr. Ahmed had a clear plan in his mind. His intention was to formulate a plan with a minimum budget in order to reduce the possibility of disapproval for financial reasons, if any. He intended to increase the agents from one to three and utilize technology for video interviews, thereby reducing the costs of recruitment.

He was determined to propose "Ten Point Employee Care Report" for further immediate implementation; however, he knew that seeking the approval from the senior management is not going to be an easy task!

\section{October 2010}

It was a sunny day in the month of October and Ahmed was satisfied with the data in hand that were collected in the last two months to validate his report and present it to the senior management. On completion of the ten point recommendation report, he immediately submitted it to the manager he reported to. To his surprise....he was heard immediately.

\section{November 2010}

After much deliberation in two meetings, the senior managers decided to give $\mathrm{Mr}$. Ahmed an audience, giving him an opportunity to emphasize the need for the implementation of his proposed ten point program.

The response of the audience was not very optimistic as the proposal was received with mixed feelings. On one hand, Ahmed was happy that the report was not out rightly rejected, but on the other hand, he was disappointed that people were not able to get the essence of that report. The result was that the report with 'no decision' was left for the next meeting with the council of senior managers set for December 23rd, 2010.

\section{December 2010}

It was yet another challenging day of December $23^{\text {rd }}$, when in the final meeting Ahmed tried his best to convince the council of managers on the relevance of his proposed ten point recommendation report. He emphasized the ripple effect of employee dissatisfaction that was disrupting productivity, hurting the bottom line need and damaging the morale. He also emphasized the need to 'cultivate and retain' the talent by building loyalty through 'employee care approach' and 'employee engagement programs' that connect employees' work contributions to tangible production outcomes, and in the end he concluded his thoughts by presenting the downsides of not focussing on such HR issues. The meeting that lasted for four hours grilled Ahmed more on the financial implications of the suggested recommendations and also on the logistics of implementing. Following the tough hours of debate, the council of managers informed Ahmed that the proposal will be discussed at higher level and it may take two to three months to inform him about the outcomes, but he was happy that he signalled a 'wake-up call'!

\section{March 2011}

Finally, the day came when Ahmed mentioned to his colleague, "I was able to stage the documents and I was able to signal a wake-up call, yet, I am not sure of the repercussions...The informal channels and grapevine effect is signalling something positive."

\begin{abstract}
Ahmed was excited to find that the recommendations have been approved, however the senior management has serious thoughts about the implementation aspects, suggesting bringing incremental changes or implementing in phases. A plan was outlined to execute the changes incrementally over the duration of sixteen months with first four points related to employee benefits, following the next four points over duration of the next six months and finally the last two points over the duration of four months. The first stage of the change program was approved to be implemented immediately. Thus, began the implementation of the ten point program which would change the face of Qudurat LLC forever and needless to mention providing a landmark in Saudi Arabian Human Resource history.
\end{abstract}

\section{September 2011}


The academic background of Ahmed did help him to do a detailed analysis and planning to introduce the change program, but the long term strategic plan and the restructuring plan certainly depend on the success of the change program. Hence, auditing the changes introduced was now the priority of Ahmed.

Moreover, the challenge before him was to get the support from the top management as organizational development, or the transformation of the organization is not possible without getting the support of the top management, and the senior management evaluates the success in numbers!

Ahmed wanted to measure the success of the change program for many reasons. Few of them were, to provide with assurance that the process is controlled, monitored and is in compliance with good practice, and further to look for opportunities to improve efficiency, effectiveness, and the overall satisfaction of people. It was also to work on the psychological contract to bridge up the gap between the expectation of the employer and the employee.

He just wished to effectively control the checkpoints between his conceptualization and implementation to ensure positive impact on business. Though he knew that formalizing the change might delay the whole process, he was certain that this will be ideal for limiting a variety of behaviours stemming from malicious acts to human error majorly due to employee dissatisfaction.

Ahmed intended to initiate a change audit considering the observable factors and using a rubric scoring system. Based on the analysis of the data received, Ahmed was enthralled to note that the implementation of the ten points program resulted in high satisfaction and motivation. Thrilled with the statement, 'for the first time we feel emotionally attached to the company because we were heard.....', Ahmed noticed that the data clearly indicated high satisfaction. The employees revealed that their needs were being met and understood to a great extent. The rest holidays, annual vacations and medical care had proved to be a great tool of success in motivating employees. $\mathrm{Mr}$. Ahmed thrilled with his success proceeded to implement the remaining points of the proposed program of employee care approach.

\section{February 2012}

With the support of top management, Ahmed successfully implemented the ten points of the employee care approach. This was ensured following the report of an audit for the change program that exhibited the success of the implementation of the employee care program or approach. February 2012 was a great month for Ahmed, yet the questions were raised and the concerns were expressed on the formulation and implementation of the practices. Regardless of few comments or criticisms, the first hand data received from employees were extremely satisfying to Ahmed, supporting his strong determination to bring positive changes at Qudurat.

\section{August 2012}

At about six months time, from the implementation of the employee care approach, the efforts of Mr. Ahmed brought great recognition to Qudurat LLC, and Qudurat was awarded for the "BEST SAUDI WORK ENVIRONMENT” award.

This award was given as a result of both an employee satisfaction survey and a fully fledged HR audit. The participation of Qudurat in this significant event was a little tough decision, considering the newly implemented policies, nonetheless, Ahmed was happy to note, that this time it was not very difficult to convince the management. This industry ranking is becoming popular in the business sector of Saudi Arabia and participating companies compete for the best working environment that implicitly means the best employer. Such competition invites more than 100 companies and the evaluators pay attention to every minute detail, especially those related to employees and work culture. The top ten companies were announced and Qudurat was proud to be chosen first among these ten! 
There was no greater happiness to Ahmed and this was the best indicator that his ten point program was a complete success. All his efforts over the past two years had paid off, and presumably he was closer to his dream of making Qudurat an employee driven workplace.

Ahmed knew that to have an employee driven workplace also requires focusing on the implementation of a high performance work system at Qudurat. This required Mr. Ahmed to carefully screen the requisites of High performance work practices (HPWP). The challenge was to take into consideration employee competence that is one of the key variables in HPWP model. On one hand, Ahmed specifically applied this fundamental rule and recruited and selected people with relevant accomplishments, cognition, values and other personal characteristics, however, on the other paw, he ensured there was an investiture in the employees by further competency development through training and instilling talent management practices for the existing employees.

Some other major step taken by Ahmed was linking the public presentation and skill development to diverse sorts of financial and non financial rewards valued by employees. Though he liked to sustain the concept of employee value proposition in place, only the cultural constraints served as a roadblock to enforce it in its true substance.

Ahmed's wide experience made him construe the fact that values driven organizational approach in guiding employee behaviour are potentially more efficacious, but the workforce diversity, with its own advantages and disadvantages at Qudurat was nonetheless challenging. He was noting that teams with diverse employees were usually taking longer to execute effectively, only at this period of time he ascertained that the organization set to minimize if not get rid of biases and favouritism and made fair and just decisions regarding work, promotions and rewards. He held open the agenda of effective team building training sessions for next phase, and considered stress management for his employees to be a more potent variable, recognizing the fact that the present era compels us to minimize conflict between work and non work demands, in other words-the work life balance. To reduce the employee stress, Ahmed introduced the relevance of quality time rather than 'FaceTime'. To further minimize the subjectivity, he ensured that the evaluations of employees were done on targets given in the beginning and by their customers' feedback rather than "face time".

\section{The Challenges Ahead.......}

Mr. Ahmed understood that Qudurat LLC had the culture 'High Power Distance'. The employees value obedience to authority and are comfortable receiving commands from their superiors, but he cannot ignore the fact that engagement, trust, loyalty and job satisfaction should be the major concerns of employers. He took efforts to open the line of communication between the different bands of employees.

Mr. Ahmed was still ruminating on the million dollar question-'How satisfied are employees at work?' His sole reason for paying significant attention to job satisfaction was his firm feeling that there is a moderate if not a strong relationship between job satisfaction and business functioning.

He recognized the key answer to resolving the problems of employee turnover, absenteeism; deviance is to save the employees happy and gratified. But, he appears to be more convinced that job satisfaction influences the Employer Branding, that is the choice to be the best employer in the community, but the concern is likewise to improve productivity.

It is already $8.30 \mathrm{pm}$ and Mr. Ahmed is still in his office with probably his last coffee of the daytime! Looking at the beautiful desert from his office window, he is thinking of the succeeding steps. He experienced that he has to figure out on psychological contract to fulfil the employee's expectations and to make clear the organization's expectations of his people and he knows that the journey is not dying to be an easygoing one........! 
Notes: The instructor should discuss the uniqueness of the Kingdom of Saudi Arabia before giving this case for reading. The below assignment questions and suggests a teaching plan will help the instructor to facilitate the classroom discussions; moreover, it will help the faculty to trigger the critical thinking and understanding amongst the students of organizational behaviour and human resource management.

\section{For Undergraduate Students:}

1. What specific changes were introduced by Mr. Wael and why?

2. How far do you agree and appreciate those changes?

3. Do you think it was easy for Mr. Wael to convince the senior council of managers? Why or why not?

4. Do you think the efforts of Mr. Wael are enough for employee satisfaction?

5. How far the culture of the country influences the efforts of Human Resource department?

6. What else could have been done by Mr. Wael to ensure employer branding?

\section{For Graduate Students:}

7. How would you manage your reward strategy to attract and retain high - performers?

8. What is the key to managing expectations amongst the national youth of the GCC region?

9. As a CEO or HR Director, how would you ensure that expatriates continue to remain engaged and productive within the organization as the proportion of GCC nationals in the workforce increases?

10. What elements would you contain in the package of a "total reward solution" within your organization, considering both -employee satisfaction and high productivity?

11. How can current approaches and measures of employee engagement be improved?

12. How will you ensure employer branding and employee value propositions to establish employee driven workplace?

\section{Acknowledgment}

The author wish to acknowledge the contribution of Mr. Ahmed, (E-mailAhmed_wael@hotmail.com) for sharing his experiences to conclude this case study.

The present case is intended to be used as the basis for class discussion rather than to illustrate either effective or ineffective handling of a management situation.

No part of this publication may be copied, stored or transmitted, reproduced or distributed in any form or medium whatsoever without the permission of the copyright owner.

\section{References}

1.Encyclopedia Britannica Online: History of Arabia retrieved 18 January 2011

2.Joshua Teitelbaum. "Saudi Arabia History". Encyclopedia Britannica Online. Retrieved 2013-01-18.

3.M. Th. Houtsma (1993). E.J. Brill's First Encyclopedia of Islam, 1913-1936. BRILL. pp. 441-442. ISBN 978-90-04-09791-9. Retrieved 2013-06-12.

4.Goodwin, Jason. Lords of the Horizons: A History of the Ottoman Empire (2003) Amazon.com

5.King Abdul Aziz Information Resource First Ruler of the House of Saud retrieved 20 January 2011

6.http://www.nationsonline.org/oneworld /saudi_arabia.htm

7.https://migration.ucdavis.edu/mn/more. php?id=3852_0_3_0

8.http://shc.com.sa/en/PDF/RESEARCH/L abor $\% 20$ and $\% 20$ The $\% 20$ Nitaqat $\% 20$ Prog ram.pdf 


\section{Appendix 1}

\section{Suggested Teaching Plan}

\begin{tabular}{|c|c|c|c|}
\hline S.No. & Activity & Instructional Strategy & Duration \\
\hline 1. & $\begin{array}{l}\text { Assign Pre Reading on the Business } \\
\text { Environment of the GCC and the } \\
\text { Kingdom of Saudi Arabia }\end{array}$ & $\begin{array}{l}\text { The assigned reading will be } \\
\text { used for initiating the } \\
\text { classroom discussion }\end{array}$ & $\begin{array}{l}45 \\
\text { Minutes }\end{array}$ \\
\hline 2. & $\begin{array}{l}\text { Discussion about the business } \\
\text { environment of the Kingdom of Saudi } \\
\text { Arabia }\end{array}$ & Class Discussion & $\begin{array}{l}30 \\
\text { Minutes }\end{array}$ \\
\hline 3. & $\begin{array}{l}\text { Discussion on topics like strategy, public } \\
\text { vs. private sector, talent management, } \\
\text { motivation, difference between HRM } \\
\text { and HRD, employee value proposition, } \\
\text { change management, OD characteristics } \\
\text { etc. }\end{array}$ & Class Discussion & $\begin{array}{l}45 \\
\text { Minutes }\end{array}$ \\
\hline \multicolumn{4}{|c|}{ Break Time } \\
\hline 4. & Discussion on Assignment Question & Group Activity & $\begin{array}{l}45 \\
\text { Minutes }\end{array}$ \\
\hline 5. & $\begin{array}{l}\text { Linking Practice to Theory } \\
\text { (Talent Management Models, OD issues, } \\
\text { Change Management, Psychological } \\
\text { Contract, Hiring and Retaining Strategy, } \\
\text { Employee Engagement, Employer } \\
\text { Branding and EVP }\end{array}$ & Class Discussion & $\begin{array}{l}20 \\
\text { Minutes }\end{array}$ \\
\hline 6. & $\begin{array}{l}\text { Wrap Up of Case Summarizing Key } \\
\text { Issues }\end{array}$ & Facilitator Driven & $\begin{array}{l}15 \\
\text { Minutes }\end{array}$ \\
\hline
\end{tabular}

